\title{
Multivocality of Saudi COVID-19 Discourse in Social Media Posts: A Socio-Semiotic Multimodal Perspective
}

\author{
Naimah Ahmad Al-Ghamdi ${ }^{a}$ \\ naghamdi@iau.edu.sa \\ College of Arts, \\ Imam Abdulrahman Bin Faisal University, Saudi Arabia \\ Areej Hammad Albawardi \\ aalbawardi@iau.edu.sa \\ College of Arts \\ Imam Abdulrahman Bin Faisal University, Saudi Arabia
}

\begin{abstract}
This paper examines the discourse of COVID-19 (also known as coronavirus) in social media posts and argues that the mediated COVID-19 discourse in Saudi Arabia enacted a variety of voices and thematic discourses that cannot be fully evaluated without reference to the locality of the sociolinguistic semiotics of the speech community. It attempts to construct the various non-verbal multivocalities in written and visual COVID-19 discourse present in 24 texts obtained from Saudi social media platforms, namely WhatsApp and Twitter, during the COVID-19 pandemic in the months of February, March and April, 2020. WhatsApp and Twitter are chosen because they are considered the platforms most used by Saudis in Saudi Arabia (GlobalWebIndex, 2020a, 2020b). The study employs a socio-semiotic approach to the analysis of collected data following Kress \& Van Leeuwen (1996), mediated discourse analysis (Norris \& Jones, 2005; Scollon, 2001) and systemic functional multimodal discourse analysis (SF-MDA). The analysis aims at integrating the social semiotics and multimodal approaches to better understand the dynamic Saudi discourse on COVID-19. The discourse on COVID-19 has revealed the dynamic multi-layered nature of governmental, individual and public voices pertaining to COVID-19 multi-discoursal themes, novel multimodal resources and the specific cultural semiotics of Saudi Arabia. The findings of the study revealed that the COVID-19 pandemic mediated discourse is relevant to the local speech community diglossic situation, cultural semiotics, social norms and integrated national identity.
\end{abstract}

Keywords: multivocality; multimodality; mediated COVID-19 discourse; social semiotics; Saudi context

\section{INTRODUCTION}

The COVID-19 pandemic emerged in Wuhan, China in December 2019 and subsequently struck the world. The COVID-19 discourse has become a global one and intra-texts on the pandemic have invaded the press and social media with the flux of media breakouts. Governments and health organisations have communicated the fear of COVID-19 to the nation in full: death tolls, quarantines, precautions, suspension of life activities and shrinking businesses are among the daily news and topics circulated among the public. With an epidemic (later pandemic) that is spreading quickly, multi-voices from the medical sector, media, authorities and the local community are in action with a variety of voices taking part in informative discourse and more importantly, reducing the panic of COVID-19, because the panic from the pandemic is real, (Kasprak, 2020).

${ }^{a}$ Main \& corresponding author 
This fear from the new pandemic is transmitted through different messages on social media, posted not only by government and health organisations, but also by netizens. It is estimated that over 3.484 billion people worldwide are using social media platforms such as Facebook and Twitter to communicate, interact, and undertake a range of formal and informal activities and practices (Mccarthy et al. as cited in Jewitt \& Adami, 2016, p. 2). In Saudi Arabia, different social media platforms, including WhatsApp and Twitter, are fast moving towards becoming the most popular messaging apps which have the affordances to enable users to exchange different types of textual, visual and audio messages. But how do these apps feature in COVID19 discourse in Saudi Arabia?

Many studies have focused on viewing social media in terms of semiotic technologies (Poulsen, Kvåle \& van Leeuwen, 2018). One approach to discourse that considers texts and the different semiotic resources used to construct them is mediated discourse analysis (Norris \& Jones, 2005; Scollon, 2001). This approach is considered an important contribution to the sociocultural approaches to digitally mediated communication. The theory behind mediated discourse emphasises that all semiotic resources, languages and actions meet at a convergence of different social practices and actions which reproduce different social identities (Gee, 2015b; Norris \& Jones, 2005; Scollon, 2001). When interacting online, people use semiotic resources, which includes visual, gestural and spatial, to reveal or conceal different aspects of their identities (Jones et al, 2015). This theory is rooted in systemic functional multimodal discourse analysis (SF-MDA).

SF-MDA is a process of meaning-making through the methods of composition, framing and salience as proposed by Kress and van Leeuwen (1996), a system for image-text logicosemantic relations as proposed by Martinec and Salway (2005), and a theme and information structure system as postulated by Halliday (1989). The present study adopts a SF-MDA to the Saudi community's Twitter and WhatsApp COVID-19 posts to unveil how they utilise textimage relations to draw their stance and distance about COVID-19 discourse in relation to their socio-semiotic traits. Previous studies in the Saudi context have focused mainly on intertextuality with less emphasis on other affordances from digital applications as semiotic resources that are employed into multimodal meanings potentials. The interplay of texts, images, stickers and emoji provides multimodal meaning potentials for the local speech community to utilise mediated tools to unfold their concern, relate to religion, invite their remote history, assimilate in their national pride, and connect to local literature and global COVID-19 discourse. The aim of this study is to address this gap in research in this area by examining different social media posts that include text, images, and Graphic Interchange Format (GIF) animations on various topics related to COVID-19 in Saudi Arabia which has one of the largest social media presences in the world. According to the latest statistics, 89.3 per cent of the population are internet users and 18.96 million, nearly 5 per cent, are active social media users (Infographics, September, 2019). Given these statistics and the gap in the literature, it is important to understand that different discourses circulate various socio-cultural features within the Saudi context by utilising a number of semiotic resources.

\section{LITERATURE REVIEW}

The rise of the internet in the early 1990s opened up new ways of communication, information exchange and socialising. It equally well provides sociolinguists with an abundance of new language-related resources and new perspectives for perceiving the workings of man on these modes of communication. Social media is only one example which has been subjected to extensive research as a rich area of application closely connected to its users and is vastly adaptive and updated to meet their needs. Participants in highly institutionalised platforms such 
as LinkedIn for example, are committed to rules and conduct that govern stylistic (linguistic and interactional) discourse features. In the context of social media platforms, the institutional (the state), social media (the public) and the private sector are open to potential one-to-one and one-to-many communication (Jensen 2015, p. 1). In elaborating on the impact of the social and institutional media, Jensen (2015) perceives the social media to be a vehicle of civil society 'articulating with itself', manifesting a third force in society, beyond state and the market (p.2).

Social media provides a platform for people to articulate their voices and ideas in various textual and modal forms, how they claim their stance and distance over an issue. In analysing the socio-semiotics of the dynamic COVID-19 discourse, heterogenous voices operate as a means of expressing solidarity and expressing anxious thoughts, such as health concerns. However, expressing these thoughts has not only emerged with the advent of social media platforms. For example, Trčková (2015) traced the metaphoric representations of the disease and portrayals of its victims, combining critical discourse analysis and the cognitive theory of metaphor to investigate Ebola discourse in two American newspapers. The findings of the study showed that the two newspapers heavily relied on a single conceptual metaphor of Ebola as war, Ebola as an animate/human being and Ebola as a natural catastrophe.

Social media platforms not only allow for everyday concerns and topics to be discussed by the public, but also open new horizons to utilise language and discourse on multiple linguistic levels. Thurlow (2006) provided a comprehensive international corpus of 101 printmedia accounts of language use in technologies such as instant messaging and text messaging. He used the label 'meta discourse' (i.e. discourse about discourse) that reveals the conceptual and ideological assumptions by which particular communication practices come to be institutionalised and understood. He came to the conclusion that such discourse is characterised by dominance of computer-mediated discourse (CMD), together with highly caricatured exemplifications of actual practice. These popular but influential (mis)representations typically exaggerate the difference between $\mathrm{CMD}$ and non-mediated discourse, misconstrue the 'evolutionary' trajectory of language change, and belie the cultural embeddedness of CMD.

Albawardi (2018) examined how young Saudi women utilised WhatsApp to communicate using language and other resources. The study examined WhatsApp exchanges including texts, images and emojis to emphasise the complexity of these interactions. The findings of Albawardi's study indicate that there is a nexus of relations, identities and cultural tools that intersect in many different ways when WhatsApp users interact.

The first few approaches that have been developed were emphasising the social context of online communication following the purely structure-centred approach to computermediated communication. Researchers, under the sociolinguistic approach, define computermediated communication interaction that takes place between humans using the computers as instruments, stressing the idea that users use language differently in different situations (Herring, 2007, 1996; Herring \& Zelenkauskaite, 2008).

Therefore, other new methodological approaches emerge to account for the more recent forms of online interaction which involve the use of different semiotic tools such as images, audios and videos. Thus, researchers focus on the new multimodal internet communication instead of text-based interaction (Jewitt, Bezemer \& O'Halloran, 2016). Multimodality is an important characteristic of most social media platforms.

A number of studies have emerged adopting multimodal approaches to online interaction and online discourse. Some of these studies focused on analysing multimodality in YouTube videos (Jewitt et al., 2016) and WhatsApp status messages (Sánchez-Moya \& CruzMoya, 2015), relying on theories from Systemic Functional Linguistics in their examination of videos, texts and emojis as different modes. These studies emphasise that each mode has a different function as a social semiotic resource. This theory emerged from Halliday's social semiotics, which was developed in 1989 and provides the groundwork for Systemic Functional 
Multimodal approaches (Kress \& Van Leeuwen, 1996), which focus on how signs combine differently in multimodal situations to provide different meanings.

The sociolinguistic approach to the investigation of computer-mediated discourse has not only been prevailing in English online interaction. Sociolinguistic approaches have also influenced research into Arabic online communication. Examples include code switching (AlKhatib \& Sabbah, 2008), gender (Strong \& Hareb, 2012) and globalisation (Allehaiby, 2013; Daoudi, 2011).

Research in this tradition has considered the social aspects of the interaction when examining digitally-mediated communication, including the identity of the user, context and the different modes that people use in their interactions. A real understanding of any interaction, however, cannot be achieved by looking just at a structural level, nor by just examining social factors. Research has to look also at ideologies and cultures, which although intangible, affect people's actions, identities and relations.

The sociocultural approach to digitally-mediated communication views online interactions as forms of social practice (Barton \& Lee, 2013), emerging from new literacy studies - an approach to literacy that considers the social and ideological perspective as essential (Barton \& Hamilton, 1998; Gee, 2014, 2015b; Street, 1984, 1995, 2003). This approach examined interactions and emphasised the plurality of these interactions or 'literacies' (Street, 1984). These practices intersect and converge at 'a nexus of practice' (Scollon, 2001, p. 10). Literacy practices, thus, includes not only the practice of writing and reading, but also the social practices of meaning making including agency, body, and objects (Barton \& Lee, 2013, p. 25).

In line with the approaches of new literacy studies, Jones et al. (2015) explain digital interaction in terms of social practices. They refer to practices online as digital practices and stress the dynamic nature of these online practices. Their definition also emphasises that these online practices are managed within 'assemblages' of tools, people and identities that join at an exact point in a situation (p.3). In these situations, people use different semiotic resources in different creative ways to create different meanings. Examples include designing Instagram posts (Manovich, 2016), sharing on Facebook (Bezemer \& Kress, 2014; Lee, 2011) and posting on Facebook (Eisenlauer, 2011).

For methodological considerations, some of these studies have made use of existing approaches to discourse such as Vásquez (2015), who examined intertextuality in online consumer reviews. In addition, there are a number of studies that have adopted mediated discourse analysis in their research (Jones, 2013; Scollon, 2001; Scollon \& de Saint-Georges, 2012; Scollon \& Scollon, 2004). The sociocultural approach has been adopted in some studies to emphasise online users' creativity in relation to mixing various semiotic resources to introduce different discourses and project identities (Jones, 2005b; Lee, 2007a; Lee \& Barton, 2011, 2012; Vásquez, 2015). Lee and Barton (2011) conclude that the multilingual and multimodal use of tags in Flickr is a way of negotiating different types of identities online that can be local and global.

\section{RESEARCH OBJECTIVES}

The researchers opted for these two social media platforms, i.e. Twitter and WhatsApp, due to their popularity in the Saudi speech community and the immediacy by which they communicated COVID-19 discourse. However, the way people interact using different modes and codes to accomplish different actions and meanings is still an unresearched area in Saudi Arabia. This study aims to fill a gap and analyse how multivocal discourse strengthens a social campaign on Twitter and WhatsApp. This research examines the multi-voicing of COVID-19 discourse in Saudi Arabian WhatsApp and Twitter, employing texts, images and digital 
resources to show how they intersect to express a variety of themes and invite multi-voices, attitudes and stances.

\section{RESEARCH QUESTIONS}

The following research questions are sought to be answered here:

1. What are the multimodal features most frequently occurring in Saudi WhatsApp and Twitter that have contributed to voicing COVID-19 discourse?

2. How far do the mediated tools add up to multivocality of the socio-semiotic COVID-19 thematic discourses on WhatsApp and Twitter in Saudi Arabia?

\section{METHODOLOGY}

The analysis of the data in this study goes through a number of stages: first, identification of themes based on classification of the collected data and second, an in-depth analysis of selected samples representing the themes found in the data. The initial examination of the data starts with identification of themes emerging from the collected data following Grounded Theory.

The collected data was further sub-classified to extract text and semiotics of an image, with or without a comment using a thematic approach. Since the study investigates how the Saudi COVID-19 social media has voiced the verbal and multimodal resources to construct meaning, thematic categorisation of the COVID-19 discourses based on their thematic content was practically appropriate. Such classification, methodologically, gave space to account for each theme, taking into consideration the intersection between the mediated semiotics and social communicative actions in the texts. Leading themes were identified in posts and tweets and accordingly classified and translated into English. These themes are part of the findings of the study and are identified under the Data Analysis section.

The identification of theme is followed by an in-depth analysis of selected texts. One or two posts are chosen for the in-depth analysis as an illustration of each theme. A multimodal analysis (of images and texts) is utilized adopting methodological tools from Systemic Functional Multimodal approaches (Kress \& Van Leeuwen, 1996). Components of multimodality and their contribution to the overall social-meaning of the discourse were identified. Moreover, the institutional and individual voices are pointed out, for example, using blending between images, texts and voice notes, to impact a social in relation to the speech community.

Due to the nature of social mediated communication, which is made up of multiple mediated actions that appropriate available tools of meaning in their discourse and the difficulties related to the data of the study comprising verbal and visual data, a clear and adequate analytical framework is needed to account for this duality of the dynamic discourse in action.

A mediated discourse analysis (Norris \& Jones, 2005; Scollon, 2001) is conducted on the collected data. Mediated discourse analysis focuses on discourse in action. Therefore, attention is given to the mediated action in posts, and how different semiotic tools are used to create different actions and meanings.

Texts were transformed (verbatim) into written texts and aligned with the visual images considering that fear and panic are performative and proactive acts meant to communicate a host of functions. Their context of use is critical to understanding participants' discourses based on the idea that discourse related to COVID-19 expressions must be located in their contexts of enunciation. Practically, the methodology implemented consisted of four steps: a) absorbing oneself in the texts, b) classifying themes, c) identifying the multimodalities and d) identifying 
social contexts. The goal was to link the digitally-mediated COVID-19 discourse on social media to the intersected e-semiotic and social practices it instantaneously performs.

\section{DATA COLLECTION}

The data for this study was obtained from two social media platforms, WhatsApp and Twitter. Twitter and WhatsApp have been selected as the social media platforms in this study due to their popularity in the Saudi speech community and the immediacy by which they communicate COVID-19 discourse. Another reason for choosing these two platforms is that they are utilised as multi-users and are multimodal. Moya et. al (2015) elaborated on the role of WhatsApp in 'enabling people to communicate in a multimodal way' (p. 53). Twitter, on the other hand, is rapidly becoming the new Google, especially in academic domains where it is being used as a virtual search platform for research.

Forty-five posts were collected over a period of ten weeks starting from the $15^{\text {th }}$ of February, when the COVID-19 crisis first surged, to the $24^{\text {th }}$ April 2020. A sample of 24 WhatsApp and Twitter posts are selected from the total sample of 45 post and tweets for the in-depth analysis. These were selected as being representative of the different themes identified.

The posts in the current data were collected from most retweeted tweets under a trending hashtag on Twitter, i.e. \# كورونا (which translates into 'Corona') during the months February, March and April 2020. Different Twitter accounts were found under this hashtag including for example governmental organizations such as the Saudi Ministry of Health (@SaudiMOH), Saudi Government Communication (@CGCSaudi) and Arabic Covid-19 (@Covid_19_Arabic), public figures such as the Minister of Health, and Saudi non-public individuals.

The same 45 posts were circulated via WhatsApp and were recurrently found in 31 WhatsApp chats obtained by the authors of this study during the same period. These included one-to-one and group WhatsApp chats between the researchers and Saudi males and females who range between 20 to 69 years old. With regard to ethical considerations, there was no need to obtain formal consent from the WhatsApp chat members because the same posts were taken from Twitter which is considered a public platform. All posts were saved as images from Twitter.

The collected posts include Arabic as well as English texts, and images that were exchanged by Saudis on different topics relevant to COVID-19. The majority of posts are in Arabic, few included both Arabic and English, and only one post included English only. The posts also contain images, texts and emojis.

\section{DATA ANALYSIS}

This section presents the analysis of the collected data. It presents the themes identified in the data in the subheadings related to COVID-19 discourses that have been derived inductively from the data. Under each subheading, an in-depth analysis of selected posts representing each theme is provided to show how different images, modes and codes intersect to create different voices and meanings circulating different local and global discourses.

Thirteen themes were identified from the collected data. The classification of the corpus of the study is data-driven and relied on the subject matter of the post. The outline of the various themes was based on the observation of the keywords that are used in a contextual domain and the source of the post which is originally a repost. For example, COVID-19 and Literature themes were easy to identify due to the employment of literary stylistic features, e.g. images and sound patterns, compared to COVID-19 and History themes which inter-textualized 
Islamic events and employed historical figures' names and lessons. The Content theme is easily recognised by knowing the source of the post, as in the case of the posts of the Saudi Minister of Health, the theme is expected to be related to healthcare and if the text extends to an image or e-tool it functions to prompt a new piece of information or a non-verbal attitude. COVID19 discourse in the present study include posts and images related to 13 themes including: healthcare, government, education, meta-discourse, humour, national, local, social, literary, international, religious, history, and nexus of discourses.

\section{DISCOURSE THEMES}

\section{CORONA AND HEALTHCARE DISCOURSES}

The first discourse that is foregrounded in Saudi social media in connection to COVID-19 discourse is related to healthcare concerns and issues. These posts were mainly informative about quarantine and how to maintain personal and community hygiene, and were exchanged from different social media platforms.

The following tweet, Figure 1, was tweeted by the Saudi Minister of Health on some COVID-19 precautions:

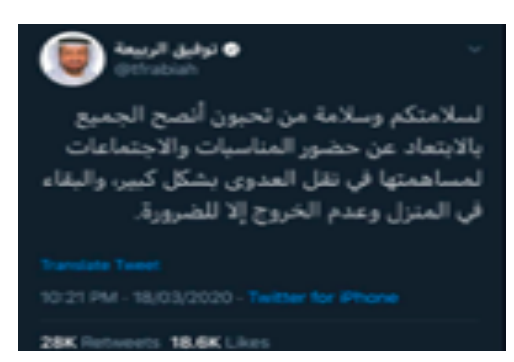

FIGURE 1. Tweet by Minister of Health

The tweet reads, 'For your safety and the safety of your loved ones, I advise all to stay away from mass gatherings, wedding occasions to prevent the wide spread of COVID-19, stay home and never go outside unless it is urgent.' Like many of the institutional, formal tweets issued in connection to COVID-19, the voice of the Minister of Health in Saudi Arabia is mediating between the speech acts of advising and informing.

The action of quarantining and staying at home have impacted a number of other social actions including education, outdoor activities, shopping etc. As a result, discourse around health issues and precautions is always present in the COVID-19 discourse.

A number of semiotic resources are utilized in the above Tweet to accomplish the action of staying at home. Choosing Twitter as a social media platform to spread this message emphasises the urgency of the action. In addition, a number of affordances Twitter provides are utilized including the use of sender photo, name and Twitter ID adds strength to the action requested since the identity of the sender is revealed multimodally using an image, a text and a Twitter ID. The sender of this tweet is known to the reader; he is the Minister of Health who is also a doctor. Colour, in this tweet, is utilized as a semiotic mode. The use of a black background is in harmony with the formality of authority and the thematic content of wedding ceremonies banning. While brighter colours are symbols of gaiety and social engagement with the world, black is the opposite. The combination of all these tools including text, image, colour and cultural identity are used to contribute to a particular discourse. It is this theme and information structure system as assumed by Halliday (1989) which are carriers of the social and cultural practices articulated within a society. 


\section{COVID-19 AND GOVERNMENT DISCOURSES}

As a reaction to the global pandemic, governments all around the world started to announce a number of orders and advisories as part of a number of national precautions and treatments. These orders and precautions announced by the government represented by different ministries were circulated to the public via different broadcast and social media platforms. Figures 2 and 3 are examples of posts issued by the governmental bodies or ministers, the Ministry of Interior Affairs and the Minister of Health, respectively. Usually such texts are prefaced with 'Breaking News'.

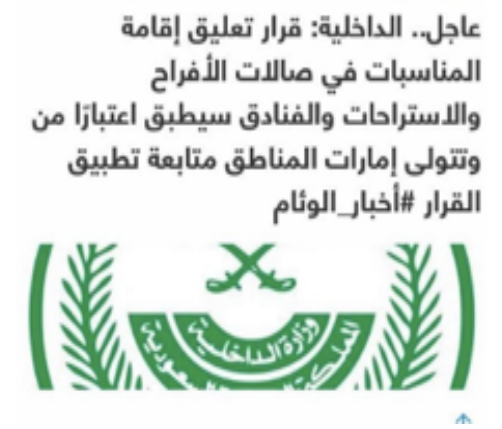

FIGURE 2. An order by the Ministry of Interior on suspension of parties

Figure 2 translates into 'Breaking News: A decree banning wedding ceremonies in halls, hotels will be in effect starting from today and governates of the provinces will follow up its application.' The use of a formal text and the use of words such as "Breaking News" and "decree" adds to the importance of the mediated action. In addition, the official logo of the ministry of Interior Affairs is presented in green with a white background is used to enforce the authority of the government. The hashtag '\#Alweeaam-News' (a private e-news channel) is used to add to the interactivity of the tweet.

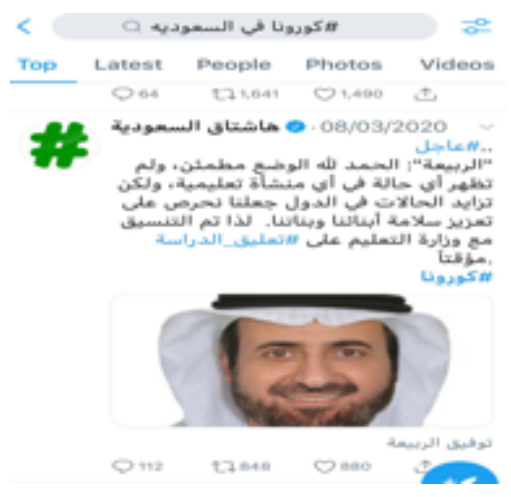

FIGURE 3. A tweet by Minister of Health

Figure 3 shows a tweet that translates into 'Breaking News: Thanks to God, no COVID19 cases were reported in schools or any educational institution; but the increased rates of cases in nearby neighbouring countries have made us more cautious and put the safety of our school kids, and our daughters first. Therefore, the coordination with the ministry of Education has resulted in temporary \#Study-suspending.' The tweet, though expressed in formal Arabic, shows the interpersonal relationship between the minister and the public and is collaboratively friendly, ('our kids, our daughters').

A number of semiotic resources are utilized to communicate the mediated action in the above tweet. Spreading the news of school suspension on a platform such as Twitter is easy and usually reaches out to various age groups in Saudi Arabia. In addition, the main and 
mediated action is emphasised as it is written in the form of a hashtag preceded by the hashtag symbol (\#) and stands out from the entire text with its blue colour.

There is a correlation of the proportion of digital resources and thematic agency (Government) in COVID-19 discourse and the interpersonal tenor expressed. The higher the status of the issuing agency, such as the Ministry of Interior Affairs, the more formal the tone, the fewer digital resources used and the less interpersonal relations expressed.

\section{COVID-19 AND EDUCATION DISCOURSE}

One of the first precautions different countries, including Saudi Arabia, have taken to stop the spread of the COVID-19, is closing schools to avoid gatherings and replacing face-to-face schooling with distance/online learning. Many on-campus projects and events were put on hold, including field trips and graduation ceremonies.

The following image in Figure 4 shows a student who is wearing a graduation gown and hat. The student's facial expression, body language and posture do not reflect the spirit of graduation that usually includes happiness and excitement, but rather, shows disappointment and sadness. This contradictory situation in the image, of both graduation and disappointment, would not be understood without the text that is superimposed on the image. It includes the following phrases: 'graduation ceremonies cancelled', 'COVID-19', 'vacation extended', 'colleges shutdown', and 'first semester results adopted as finals'. The image combined with the text reflects the feelings of some graduates-to-be during their quarantined days.

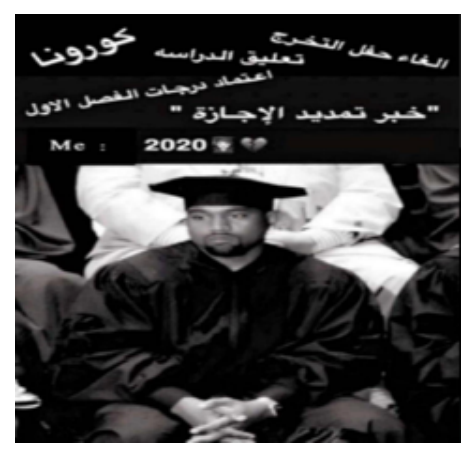

FIGURE 4. Image of a graduate

The multimodality in the image is created by the flat animated GIFs which strongly communicate the gloomy facial expression of a famous singer associated with the scattered texts. The multivoicing injected by the use of texts in Figures 4 and 5 expresses the feelings of 2020 graduates. It triggers juxtaposed feelings of sympathy and confusion.

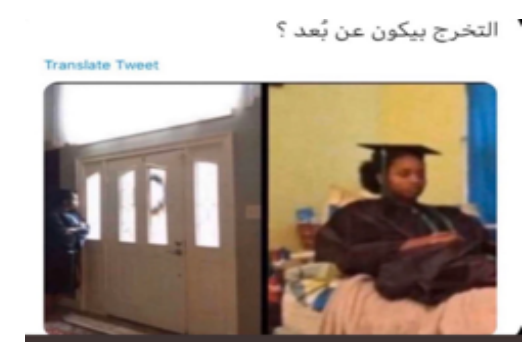

FIGURE 5. image of a sad female graduate at home 
Social distancing of graduation ceremonies was an issue negotiated vigorously in Saudi academic domains. The image in Figure 5 above enacts the imposed social distancing. Social distancing was implemented by Saudi higher authorities to slow down the spread of the virus. The tweet incorporates two images in one; the graduate is in her room wearing a graduation gown and the second half of the image is of the girl looking to the outdoor space. The image is very intense and voices the graduate's intense feelings of grief, too powerful to be expressed verbally. The place semiotics as proposed by Scollon, (2001) assonates where in the physical world the graduate would love to be and where in fact she is located. The image is emotively powerful to be expressed verbally and geosemiotically takes meaning from the way subjects or objects are placed.

\section{COVID-19 AND META-DISCOURSE}

A great flow of news and rumours on different newspaper, broadcast and social media platforms took place as a reaction to the spread of COVID-19 in different countries. In the midst of these fast-paced types of news on COVID-19, people have expressed that they are not content with a lot of information that is sometimes seen as fake or contradictory. The WhatsApp post below in Figure 6, translated into, 'I wish the government suspends WhatsApp instead of school - exhausted from rumours', shows that people not only demonstrate that they are being overwhelmed by the amount of news they are receiving but also are expressing some critical remarks towards the type of news they are receiving.

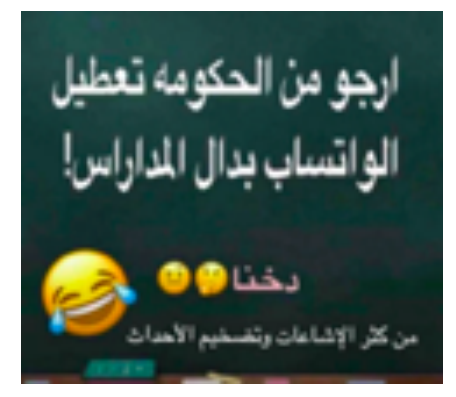

FIGURE 6. meta-discourse

Figure 6 communicates the action of rejecting fake news. A number of discourses circulates this action. There is a meta-discourse, i.e. discourse on discourse or language about language, realized by the sender as well as reader created by the collective voice used to evaluate news circulated via WhatsApp. In addition, there are a number of voices implied in this voice that are multimodally represented through different fonts and sizes. Different frames, i.e. tones, are also attached to different voices with the help of emojis. The interplay of tools, voices and frames contribute to the creation of nexus of discourses.

\section{COVID-19 AND HUMOUR}

Humour in WhatsApp or Twitter posts relies on the audience expectations, digital resources and textual features presented. In Figure 7 below, image irony is created by utilisation of an amalgam of colours, symbols and text style: the green and white background, denoting the Saudi national flag, voicing a formal authority by the use of the logo of the Ministry of Health on the upper-left side, and the use of the colour red calling for the audience attention. The different texts engage the reader through the conditional structure, 'for your safety from novel COVID-19, stay at home'. The phrase 'stay home' is in the foregrounded sub-text. The 
foregrounded green sub-text is voiced humorously in local Arabic dialect, 'settle at your homes, you Covid-idiots scientific reason does not work well with you' and an upside-down emoji. Figure 7 illustrates the juxtaposition of colours in relation to audience visual expectations.

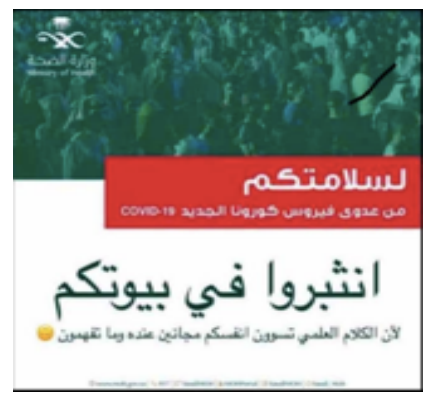

FIGURE 7. Stay at home post

Another example illustrating the employment of such a shift from formal to informal style can be seen in Figure 8 below:

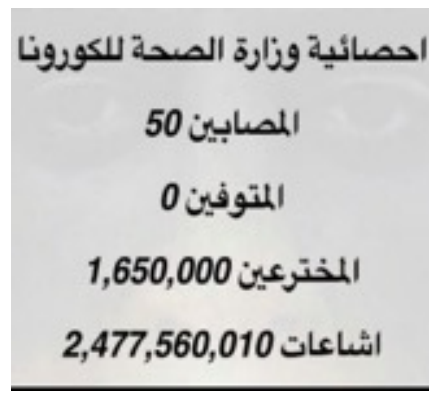

FIGURE 8. A statistic by Ministry of Health

Figure 8 is from WhatsApp showing Arabic text and numbers related to daily COVID19 cases which can be rendered into, 'Statistics of COVID-19 cases from the Ministry. Infected 50 / Death 0 / Inventors 1,540,000 / Rumours 2,477,560,010'. The sequencing of information and digital irony concerns the wide spread of rumours in comparison to inventors of recovery recipes, death roll and infected persons. The choice to resort to digital numbers can be seen under systemic functional multimodal discourse analysis as a tool used to amplify certain social actions during Covid-19 crisis. These numbers are understood as signs that signify the augmentation of a critical social practice.

Another way of creating humour is via the use of comics related to COVID-19 in the Saudi context as illustrated in Figure 9 below:

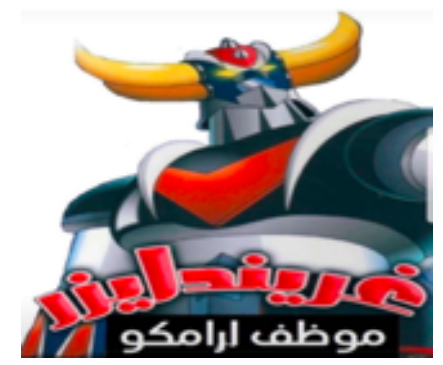

FIGURE 9. Cartoon superhero figure 
In Figure 9, humour emerges from the understanding of the situation after the COVID19 attack. The Aramco oil company did not suspend its workers and continues to secure the safety and security of its workers. Besides ensuring the continuity of energy supply upon which world companies rely, the giant robot sticker of Grendizer interfaces with Spacer to achieve the difficult tasks.

In addition, among the topics that people discuss with humour in WhatsApp is weight gain. Due to quarantines and curfews required by the country, many outdoor activities, including gym attendance, were put on hold. Moreover, people at home are using food and cooking as one of the limited forms of entertainment available. The following image in Figure 10 has the image of an elephant and an Arabic text:

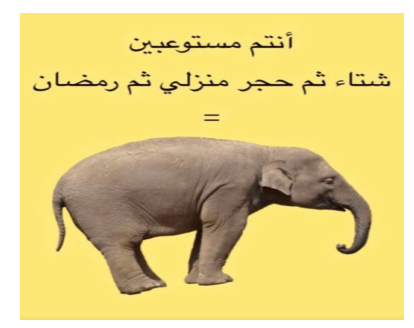

FIGURE 10. An elephant

The text translates as, 'I can't really believe! Winter time, then quarantine, then Ramadan around the corner', followed by an image of an elephant which is associated with the concept of heaviness and big size. The public is trying to find laughter amid the panic through funny jokes about gaining weight while quarantined; the combination of three seasons for overeating are winter time, curfew and the coming holy month of Ramadan where Muslims round up their favourite traditional dishes for breakfast (Iftar).

There are a number of semiotic tools that are used to tell this joke, i.e. the mediated action. There is the Arabic text that is structured as a math problem. This math problem does not result in a text but in an image of an elephant. Humor is created by linking recurrent themes attached to elephants.

\section{COVID-19 AND LOCAL DISOCURSE}

Another voice that emerges in the COVID-19 discourse is the local voice, represented in text as well as images. At the same time, an awareness of the multicultural and multilingual composition of the local society is reflected. Figure 11, for example, shows a female character wearing traditional Islamic clothing common in Gulf countries and known as an 'abaya'. This local character is giving advice COVID-19 that is written in Arabic and English to address an audience of Arabic and non-Arabic speakers. This utilisation of different languages is reflecting the idea of social inclusion. Not only is the type of text utilised to reflect the social composition but text size is also used. The size of the text in the following image is used differently in different languages: a large font with Arabic text and a smaller font with English, reflecting the population difference of Arabic speakers versus English speakers. Three voices are intersecting in the text used in this post: the first type of language used, Arabic, is informal and colloquial, the second, using English alongside the Arabic and third, the use of different fonts, is noteworthy. 


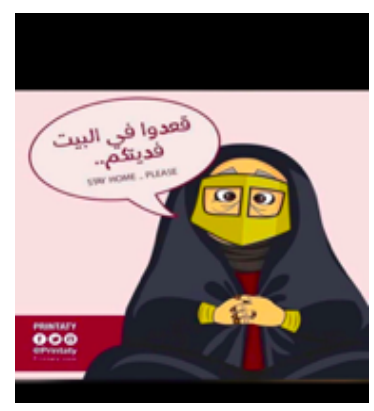

FIGURE 11. Local discourse Stay home, I plea you

The multimodal image is communicated in both Arabic and English via WhatsApp which intends to make use of the old woman as a symbol of the wisdom of old age. The old lady appears in traditional Gulf costume and veil, the voicing is in direct polite imperative through the request form plea which is the semi-equivalent translation of, 'May I redeem you,' in the local Gulf Arabic, expressing extreme invocation. Intertextuality in the post is quoted by the Saudi public using Printaty, an online shopping blog logo. The public make use of available resources in the press to report the pressing thought of 'stay at home'. The linguistic voice of the polite imperative coming from an old lady echoes the social dimension of the Saudi local culture, where the sign supports the intended message and where, as noted by Hazaea et al. (2014) 'fear of loss of cultural identity is emphasised by social actors' (p. 4).

Another example drawing on nostalgic childhood memories in Saudi Arabia can be seen in Figure 12 below:

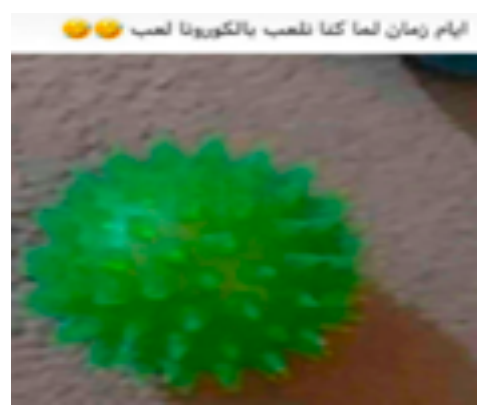

FIGURE 12. A green ball

The image inter-textualizes an inanimate object (a rubber ball) and the ironical remark which clearly represents the opposite of the current situation with COVID-19 being the agent of massive horror. The meaning in this post is created by re-signifying the ball for specific humorous purposes. The ball here is not used to signify a toy but rather to symbolize the virus. The funny comment (in the old days, we used to play with the COVID-19 ball playfully) relies heavily on shaping meaning using an object that looks like COVID-19. The implication of the voice in that WhatsApp post is that nothing lasts for ever.

\section{COVID-19 AND NATIONAL DISCOURSE}

One of the most apparent discourses that the collected data draws upon is the national one, i.e. Saudi. Emphasis on concepts such as loyalty and citizenship are used in the fight against COVID-19. Heroism is enacted in images with the national flag and colours, the map of Saudi Arabia and text that urges people to stay at home, as shown in the following post (Figure 13): 


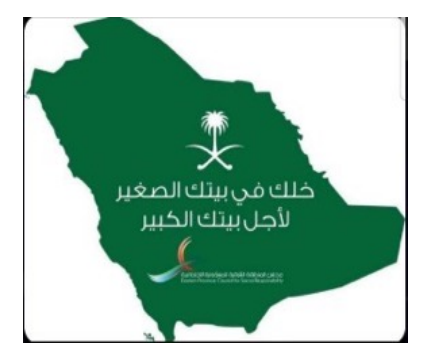

FIGURE 13. Map of Saudi Arabia

The discourse of COVID-19 lends itself to the expression of Saudi national identity. The image is circulated from WhatsApp. The green reflected over the Arabian Peninsula is the national Saudi flag colour and there are symbols of power (sword) and growth (palm tree). The text in the white font of the national flag rhythmically reads, 'Stay in your small house for the sake of your big home.' The use of colour functions not only as a form of Saudi national identity, but also for the construction of a sense of shared belonging across the whole community. The foregrounding of national identity via colour is a premeditated call for national identification. The quote alludes to positive associations for all Saudis.

Understanding the context of the WhatsApp post and the macro-context of the Saudi authority announcing a nation-wide curfew and the societal reaction to it is essential in reducing the tension between the image and text. In Figure 14 below, the in-text headline reads in local Arabic, 'We ought to cut rates to zero', followed by the verbal text, 'By abiding to quarantine, we will score' and then an image of e-tool of calculus ' 01 ' is shown. Then it is back to verbal text, ' 0 new cases, 0 critical cases, 0 under treatment, 0 deaths. Inshallah ( by the will of God).'

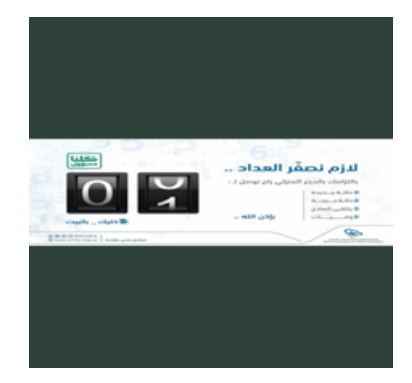

FIGURE 14. Make it a zero

The collected data also contains texts that articulate national pride in the doctors, nurses and soldiers in the field of battle as represented in Figure 15 below. The translation is, 'Doctors, nurses and soldiers who must dominate the face of social media not the fashionistas.'

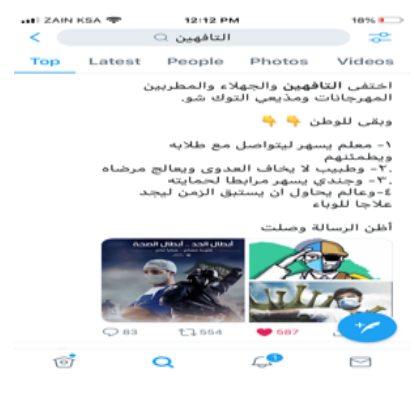

FIGURE 15. Post on doctors 
The analysis of the collected data reveals that national discourse is cultivated by the utilisation of text, images, colour and cultural identities.

\section{COVID-19 AND SOCIAL DISCOURSE}

A number of social categories and activities are affected by the precautions taken against COVID-19. Weddings were suspended to avoid people gathering and the spread of the disease. The following post (Figure 16) highlights this issue with a humorous touch:

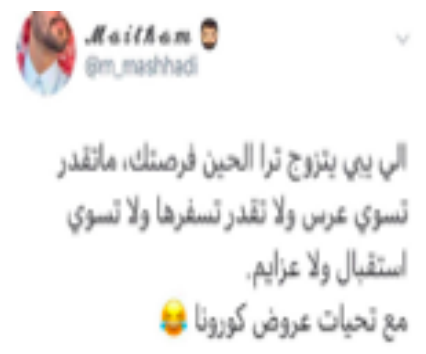

FIGURE 16. Getting married during COVID-19 Pandemic

The tweet reads, 'If you want to wed, now it is the perfect timing. No wedding party, no travel, no reception and no wedding banquet.... with the compliments of COVID-19 Promotional Offers (smiling face emoji).

The thematic content of the tweet inter-textualises, 'One man's loss is another man's gain', which negotiates one of the salient social concerns of the Saudi community, the excessive costs of wedding rituals. The source of sarcasm is that marriage ceremonies are postponed in Saudi society and banned in consideration of the current threat of COVID-19; the tweet triggers youth criticism of the current state of wedding burdens. The sarcasm involves a contradiction between the timings of the proposal and the presentation of the offer, 'COVID19 Promotional Offers' and the intended message of disapproval.

\section{CORONA AND INTERNATIONAL DISCOURSE}

The fact that COVID-19 is a pandemic entails a spread of similar discourses worldwide. Concepts such as quarantine, self-isolation, curfews, home shelter were heard and used globally. Making use of the 'before/after' technique as in Figure 17 below, are two panels: verbal TV news reporting, 'COVID-19 only kills elderly', and a macro-text comment saying, 'the ugliest means of news awareness.'

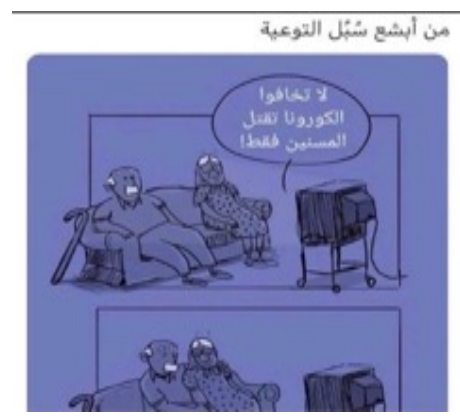

FIGURE 17. Old people and COVID-19 
Another international discourse is presented in the following post (Figure 18):

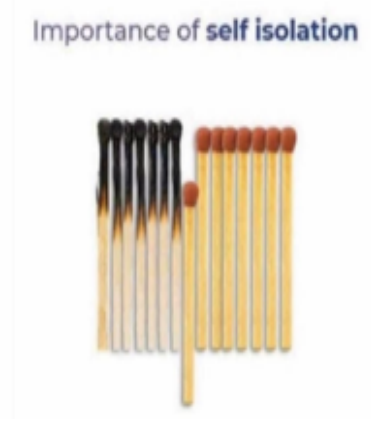

FIGURE 18. social distancing

The importance of self-isolation is represented through a visual post (Figure 18). The image is of a line of matches with one match lowered. This realignment of matches prevents the spread of fire due to having only one match distanced from the others. This visual representation is a demonstration of how social distancing contributes to stopping the spread of the pandemic.

\section{COVID-19AND HISTORY}

One of the discourses that is used in the fight against COVID-19 is history and local historical events. The following post (Figure 19) draws upon the Islamic event of the battle of Uhud, which ends with losing due to not 'staying in place':

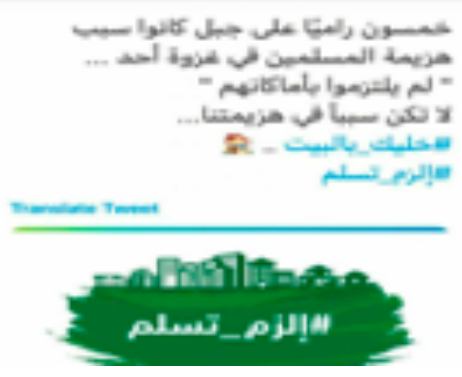

FIGURE 19. Stay home, stay safe

The tweet employs two hashtags, the symbol '\#' is used twice for tagging the in-text which is written in formal Arabic which translates as, 'Stay home, stay safe'. The background of the national green colour connotes the positive dispositions of the national Saudi flag, friendly eco contexts etc. The verbal text reads, ' 50 archers over a mountain (the mountain of Uhud in Al Madinah, the second holiest city in Saudi Arabia) were the cause of defeat in the battle of Uhud (the second battle between Muslims and disbelievers in the year 62 Common Era - they did not abide to the instructions of the prophet Muhammad (PBUH). So, do not be the cause of our defeat \#Stay home - Stay Safe (in an informal local Arabic) and \#Oblige - be safe' in formal Arabic. The multimodality is complex here and invites a host of multilayering of inter-textualisation in the use of verbal text and image, in reflecting the thought diglossically in two codes and more significantly, in reflecting upon the historical context of the battle of Uhud, the second military encounter between Muslims and unbelievers of Mecca. Such historical inter-textualisation refers back to the Islamic cultural heritage through mapping the two contexts, one from remote history through to the present COVID-19 context. There is 
similitude in the two 'battles', of Uhud being close to a victory for Muslims, yet the archers of Uhud leaving their camp unprotected causing the defeat, and the advice to please stay home and not become the cause of defeat by COVID-19. The two hashtags texts interconnect semantically and spatially; it is also the way they are situated in a single tweet that connects the past to the present. It is this systemic functionality of the text and its semiotics, that Norris and Jones (2005) advocate, which place the Saudi Covid-19 historical discourse into action.

Replies to this tweet were massive, recognising that victory is not in winning but in drawing lessons from defeat and loss. That is why after winning the first battle in Islamic history, the prophet Muhammad wanted his followers to learn a hard lesson, (of victory against the self) giving God the glory of winning and defeat equally. Prophet Muhammad sets the ethics of war in peace and in war times. Following the ethical standards of the messenger of Allah, defeat is a mercy, a source from which to draw thousands of lessons.

COVID-19 AND RELIGIOUS DISCOURSE

The analysis of the collected data shows that the COVID-19 pandemic not only revolves around health discourse but also religious discourse in the Saudi context. The following post (Figure 20) is an example:

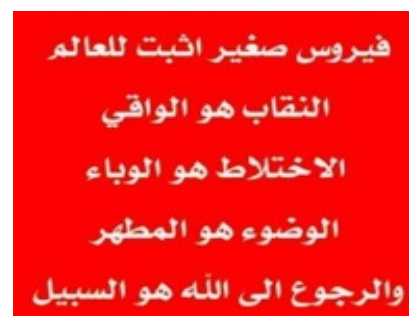

FIGURE 20. COVID-19 virus and face covering

The WhatsApp micro-text is reflected against the colour red. It reads, 'A tiny virus proves to the world that, Veil is the mask, intermingling is the epidemic, ablution disinfects, and turning to God is the way out.' The interactive hypertext colour appropriates the thematic content of the discourse. Selection from the affordances of colours makes red suitable for the meaning the post wants to construct. It is this appropriation of semiotic resources (colour) and text that voiced Saudi relationship with their social and cultural identity.

Another example of COVID-19 discourse intersecting with religious discourses can be seen in Figure 21:

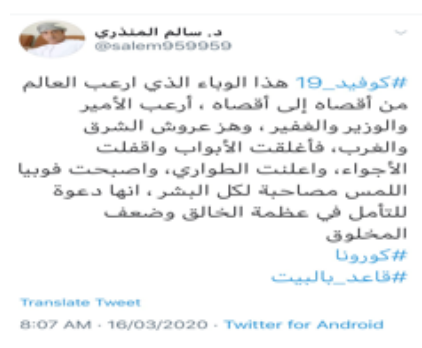

FIGURE 21. An invitation for contemplation 
The twitter hashtag was \#COVID-19 and the in-text reads:

This pandemic which terrified the world, east and west, frightened the rich and the poor, rocked the eastern and western thrones, doors and sky-ways were shut down, emergency was announced, Haphephobia prevailed. It is time to reconsider the weakness of man against the greatness of God.

The text structure of problem-solution informatively echoes the extent of the panic that swept the east and west, the poor and the rich. Moreover, the text structure is patterned with emphatic rhymed phrases, assonance and alliteration. The anxiety of the virus that breeds haphephobia, the fear of touch, recalls the striking fact of man's fragility.

\section{COVID-19 AND LITERATURE}

The discourses on COVID-19 also intersect with discourses on literature. The symbolic, figurative and metaphorical meaning of the pandemic has attracted the reflection of literary Saudi figures. The following (Figure 22) is a tweet from the collected data illustrating the intersection of COVID-19 and literary discourses:

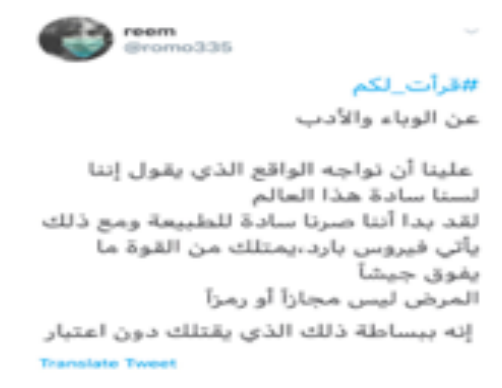

FIGURE 22. Literature and COVID-19

The tweet reads as follows:

The Epidemic and Literature: We have to face reality that we are no more the masters of this world. We are not the masters of nature, zoom it out, a tiny, cold blooded virus has the strength of an army. The disease is not metaphorical or symbolic, it simply that hangs you by a thread.

The hashtag is an in-text tagging which is a type of metadata for managing interaction with others. The tweeter posted the hashtag under '\#I read for you' and categorised it under The Epidemic and Literature addressing a particular speech community interested in this specific topic. The post communicates the dreadful revelation that man is no longer the master of earth. COVID-19, though so tiny, has the massive authority to dictate death cold heartedly. Such literary tweets rely on generating change in the speech community's perception of animate-inanimate dynamic relations. This idea can be also illustrated in Figure 23 below:

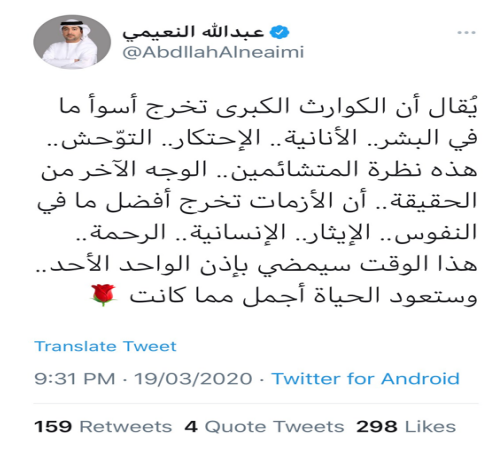

FIGURE 23. Disaster and humanity 
The text translates as:

'Crisis brings out the worst in humans ... being selfish and egotistic ... monopolistic... savagery ... this is the pessimistic view of some. The other side of the truth is that crises bring out the best in us... extending hands to others, feelings of mercy and human touches ... this hardship will pass by the will of God, the One and Only, life will come back more beautiful than before.'

The use of the rose emoji is used to frame the text with hope and optimism. Though the tweet presents two opposing attitudes to the crises, the optimistic and pessimistic, the optimistic side wins by virtue of receiving more 'information diffusion'. Written in a literary standard Arabic, the tweeter emphasises the brighter side of the disasters, the support of God and the enormous community solidarity.

\section{NEXUS OF DISCOURSES, NEXUS OF SEMIOTIC RESOURCES}

It is clear that it is difficult to separate discourses when talking about COVID-19. Various discourses intersect as different semiotic resources, including text, images, emojis, colours and symbols are used. Each tool used in composing the final product has its own history and brings about different cultural identities as illustrated in Figure 24:

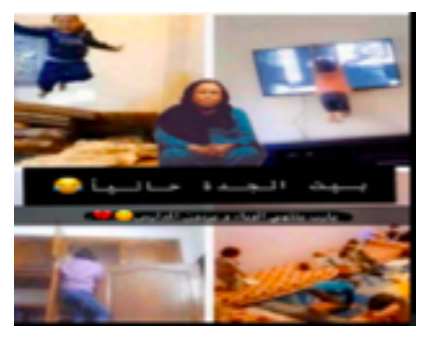

FIGURE 24. Grandmother's house

This post shows that the multi-layered quality of the image corresponds to multivocality and the nexus of various social practices and actions. The image contains a sticker of a famous Arab actress repressing the semantic meaning of drama/dramatic situation collaged on photos of misbehaving children. This collage of images is also layered with texts and emojis. The text reads, 'The current status of grandmother's house - I pray COVID-19 ends and my grandkids go back to school.' The theme revolves around the impact of school closures on grandmothers after the COVID-19 pandemic.

\section{DISCUSSION}

In this paper, a thematic analysis followed by a mediated discourse analysis is conducted on a number of posts on social media about the pandemic, COVID-19, taking place in 2020. We argue that multivocality does not only emerge from intertextuality but also from using different semiotic tools that bring in different identities and discourses.

The data collected from Twitter and WhatsApp posts recorded the utilisation of mediated images in which the use of tools display the various features or affordances of these two social media platforms. Users of the WhatsApp platform, for example, utilise the affordances that the application makes available, such as the use of text, image, audio and video to create not only a multimodal way of communication, but also a multivocal discourse.

The thematic analysis shows that the analysed posts revolve around a number of COVID-19 discourses. These include, as seen in the analyses above, topics on health, social relations, education and religion. These discourses were hard to decipher since they are 
interrelated. Overlapping voices correspond to multidimensionality of COVID-19 discourse as the study traced 13 varied themes representing the socio-cultural semiotics of Saudi Arabia in relation to COVID-19 discourse.

Another important finding in this study is relevant to the community national and social assimilations to COVID-19 discourse that has recorded high dominance in the data (Figures 13, 14, 15, 16, 19, 20 and 21). It seems that the COVID-19 crisis ignited a sense of national and social unity in the Saudi community, reflected in the form and content of the data (signs, national green colour, images and texts). Such national and social behaviour, despite anxiety, strengthens the community to collective feelings that were not felt years ago.

The thematic analysis of COVID-19 discourse correlates to the degree of formality of the code used. The health discourse, for example, is seen as more formal, pertaining mostly to institutional norms, whereas social topics are more informal and related to public multivoicing. For example, the use of slang in WhatsApp posts aims at invoking solidarity and stressing national identity as in the example in Figure 3, where the social dimension of the Saudi traditional culture supports the intended message and the post with the green and white colours of the national flag in Figure 7 with the informal word 'انثبروا', '?nӨbrou', meaning, 'Settle down at your homes you Covid-idiots'. The paradox created from the 'انثيرو ' post with the formal logo and heading of the Ministry of Health is juxtaposed with the informal slang word.

Such juxtaposing is made accessible, even in formal discourse contexts, via digital resources which give a sense of freedom, despite limited space in the post, to exercise power relations (through the use of imperative and slang) discourse. In addition, religious intertextuality in relation to COVID-19 discourse is appropriated expressively and rhetorically to relate to historical or religious texts.

We can say that the multivocality and intertextuality comes not only from text but from image, colours, symbols and use of clothes and other semiotic resources that carry different social and cultural meanings. This nexus of different tools, identities and discourses creates a rereading of COVID-19 appropriated to the Saudi cultural context. The dominant green colour of the national flag is always used as the background of governmental, health, national, social, religious and historical discourses, as in Figures 1, 2, 3, 6, 7, 13, 14, 15 and 19. The symbolic semiotics of the colour enforce authority of the government, have positive connotations for Muslims and add interactivity to the post. Red, as the background of Figure 12, corresponds to the religious content of the post, 'A tiny virus proves to the world that, Veil is the mask, intermingling is the epidemic, ablution disinfect, and turning to God is the way out.'

\section{CONCLUSION}

The current study provides an examination of the multi-voicing of COVID-19 discourse in Saudi WhatsApp and Twitter text-image posts adopting a Systemic Functional Multimodal approach. The results revealed that multimodal ways of communicating COVID-19 discourse pertain to multi-voicing of thirteen themes identified in the data. These themes amalgamate many semiotic resources (text style, colour and symbols) in a single post which assonate social voices, stances and cultural-specific imprints. Moreover, the mediated tools, such as colours and images set the community free to articulate concerns, attitudes, pride in national identity and power relations.

Power relations are juxtaposed in formality of style, affordances from digital applications and colours, often within a single post, to unravel the public ideology and attitude towards existing institutional authorities such as the Ministry of Health. Text-visual modes of landscaping national identity are celebrated in the green colour of the national Saudi flag as the background of governmental and non-governmental themes alike, to emphasise national 
identity and voice variety of semiotics limited to Saudi and Arabic nations. It is this interplay between the multivocal and multimodality that is functional in understanding the COVID-19 discourse in relation to the speech community's diglossic situation, cultural semiotics and integrated national context. Though the study provides content analysis of Saudi COVID-19 discourse in relation to multimodality as a feature of social media, consideration of the animated videos and audios is beyond the scope of the current study. Moreover, the study is limited to 24 posts collected over a period of thirteen weeks. A wider sample may reveal a diversity of themes related to COVID-19 that might be informative of the dynamic relation between multi-voicing and multi-modality. Future research would benefit from the use of a larger sample from cross-cultural contexts.

\section{ACKNOWLEDGEMENT}

We would like to thank Imam Abdulrahman bin Faisal University for its institutional support presented by the Deanship of Scientific Research for the fast-trace COVID-19 grant of this research project N.2020-011.

\section{REFERENCES}

Albawardi, A. (2018). The translingual digital practices of Saudi females on WhatsApp. Discourse, Context \& Media. 25 (68-77).

Al-Khatib, M. A., \& Sabbah, E. H. (2008). Language choice in mobile text messages among Jordanian university students. SKY Journal of Linguistics, 21, 37-65.

Allehaiby, W. (2013). Arabizi: An Analysis of the Romanization of the Arabic script from a sociolinguistic perspective. Arab World English Journal, 4(3), 52-62.

Barton, D., \& Lee, C. (2013). Language online: investigating digital texts and practices. Routledge.

Bezemer, J., \& Kress, G. (2014). Young people, Facebook and pedagogy: Recognizing contemporary forms of multimodal text making. In M. Kontopodis, C. Varvantakis, M. Dafermos, \& C. Wulf (Eds.), Youth, tube, media: Qualitative

insights and international perspectives. Berlin: Waxmann.

Daoudi, A. (2011). Globalization, computer-mediated communications and the rise of e-Arabic. Middle East Journal of Culture and Communication, 4(2), 146-163.

Jewitt, C., \& Adami, E. (2016) Special Issue: Social media and visual communication. Visual Communication, $15 \quad$ (3). pp. 263-270. ISSN 1470-3572 https://doi.org/10.1177/1470357216644153

Fairclough, N., Mulderrig, J., \& Wodak, R. (2011). Critical discourse analysis. Discourse Studies: A Multidisciplinary Introduction, SAGE Publications Ltd.

Eisenlauer, V. J. (2011). Multimodality and social actions in 'personal publishing' text: From the German 'poetry album' to Web 2.0 'social network sites'. In K. L. O'Halloran \& B. Smith (Eds.), Multimodal Studies: Multiple Approaches and Domains (pp. 131-152). Routledge.

Gee, J. (2014). An introduction to discourse analysis: Theory and method. Routledge.

Gee, J. (2015). Social linguistics and literacies: Ideology in discourses. Routledge.

GlobalWebIndex, (2020a). Forecast of the number of WhatsApp users in Saudi Arabia from 2017 to 2026. Statista. https://www.statista.com/forecasts/1145951/whatsapp-users-insaudi-arabia

GlobalWebIndex, (2020b). Leading countries based on number of Twitter users as of July 2020. Statista. https://www.statista.com/statistics/242606/number-of-active-twitterusers-in-selected-countries/ 
Halliday, M. A. K., \& Hasan, R. (1989). Language, context and text: Aspects of language in a social-semiotic perspective (2nd ed.). Oxford: Oxford University Press.

Hazaea, A., Noraini, I., \& Fariza, N. (2014). Discursive Legitimation of Human Values :Localglobal Power Relations in Global Media Discourse. Gema Online Journal, 14, (1), 171187

Herring, S. (1996). Two variants of an electronic message schema. In S. Herring (Ed.), Computer-mediated communication: Linguistic, social, and cross-cultural perspectives (pp. 81-106). John Benjamins Publishing Company.

Herring, S., \& Zelenkauskaite, A. (2008). Gendered typography: Abbreviation and insertion in Italian iTV SMS. IUWPL7: Gender in language: Classic questions, new contexts, 7392.

Jewitt, C., Bezemer, J., \& O'Halloran, K. L. (2016). Introducing multimodality. Routledge.

Jones, R. H. (2005b). 'You show me yours, I'll show you mine': the negotiation of shifts from textual to visual modes in computer-mediated interaction among gay men. Visual communication, 4 (1), 69-92.

Jones, R. H. (2013). Health and risk communication: An applied linguistic perspective. Routledge.

Jensen, K. B. (2015) What's Social about Social Media?. Social Media and Society. 1-2

Kasprak, A. (2020) Did an Infectious Disease Specialist Write 'I Am Not Scared of COVID19’?. Snopes. https://www.snopes.com/fact-check/abdu-sharkawy-coronavirus/

Kress, G., \& Van Leeuwen, T. (1996). Reading images: The grammar of visual design. Routledge.

Lee, C. (2007a). Affordances and text-making practices in online instant messaging. Written Communication, 24 (3), 223-249.

Lee, C. (2011). Micro-blogging and status updates on Facebook: Texts and practices. Digital discourse: Language in the new media, 110-128.

Lee, C., \& Barton, D. (2011). Constructing global identities through multilingual writing practices on Flickr. com ${ }^{\circledR}$. International Multilingual Research Journal, 5 (1), 39-59.

Lee, C., \& Barton, D. (2012). Multilingual texts on Web 2.0. The case of Flickr.com. In M. Sebba, S. Mahootian, \& C. Jonsson (Eds.) Language mixing and code-switching in writing: Approaches to mixed-language written discourse, (pp 128-145). Routledge.

Manovich, L. (2016). Subjects and styles in Instagram photography (Part 1). Retrieved from http://manovich.net/content/04-projects/090-subjects-and-styles-in- instagramphotography-part-1/1m_instagram_article_part_1_final.pdf

Martinec, R., \& Salway A. (2005). A system for image--text relations in new (and old) media. Visual Communication 4 (3): 337-371

Norris, S., \& Jones, R. H. (2005). Methodological principles and new directions in MDA. In S. Norris \& R. H. Jones (Eds.), Discourse in action: Introducing mediated discourse analysis (pp. 201-206). Routledge.

Poulsen, S., Kvåle, G., \& van Leeuwen, T. (2018). Special issue: Social media as semiotic technology, Social Semiotics, 28:5, 593-600 https://www.tandfonline.com/doi/pdf/10.1080/10350330.2018.1509815?needAccess= true

Sánchez-Moya, A., \& Cruz-Moya, O. (2015). "Hey there! I am using WhatsApp": A Preliminary study of recurrent discursive realisations in a corpus of WhatsApp statuses. Procedia-Social and Behavioral Sciences, 212, 52-60.

Scollon, R. (2001). Mediated discourse: The nexus of practice. Routledge.

Scollon, R. (2002). Intercultural communication as nexus analysis. Logos and Language: Journal of general linguistics and language theory, 3(2), 1-17. 
Scollon, R., \& Scollon, S. (2004). Nexus analysis: Discourse and the emerging internet. Routledge.

Scollon, S., \& de Saint-Georges, I. (2012). Mediated discourse analysis. In J. Gee \& M. Handford (Eds.), The Routledge handbook of discourse analysis, (pp. 66-78). Routledge.

Street, B. (1984). Literacy in theory and practice (Vol. 9). Cambridge University Press.

Strong, C., \& Hareb, H. (2012). Social media fashion among digitally fluent young

Arabic women in the UAE. Journal of Middle East Media, 8(1).

Thurlow, C. (2006). From statistical panic to moral panic: The metadiscursive construction and popular exaggeration of new media language in the print media. Journal of ComputerMediated Communication, 11 (3), 667-701.

Trčková, D. (2015). Representations of Ebola and its victims in liberal American newspapers. Topics in Linguistics. V10, Issue 16. https://doi.org/10.2478/topling-2015-0009

\section{ABOUT THE AUTHORS}

Naimah Al-Ghamdi is an Assistant Professor in Sociolinguistics, Imam Abdulrahman bin Faisal University, Saudi Arabia. Recently obtained her Senior Fellowship in Higher Education from Advance HE Academy, UK, 2020. She is the Senior editor of the International Journal of Language \& Literary Studies (IJLLS) and JLTS.

Areej Albawardi is an Assistant Professor in Applied Linguistics at Imam Abdulrahman bin Faisal University, Saudi Arabia. She is the Head of the English Language Department. She is a $\mathrm{PhD}$ graduate from University of Reading, UK. 